\title{
The 15th International Conference on Renewable Resources and Natural Biotechnologies
}

DOI: $10.1134 / \mathrm{S} 0040579510020168$

The 15th International Conference on Renewable Resources and Natural Biotechnologies was held on June 8-9, 2009 in Poznan (Poland) under the auspices of the Ministry of Agriculture of the Saxony-Anhalt Land (Germany). The conference was organized by OHMI Consulting $\mathrm{GmbH}$ (Magdeburg), BIO Mitteldeutschland $\mathrm{GmbH}$, and the Institute of Natural Fibers and Medicinal Plants (INF).

Professor R. Kozlowski (Director of INF) and Prof. F. Pudel (OHMI Consulting $\mathrm{GmbH}$ ) were the cochairmen of the conference. The members of the Scientific Committee were scientists from Poland, Germany, Great Britain, Bulgaria, Russia, Canada, and Hungary. The Russian member of the committee was Prof. Zaikov.

The scientific program of the conference included 22 lectures and 22 posters.

The first two lectures were devoted to the present state of affairs in the field of renewable resources and plant biotechnologies in Poland and Germany.

The following issues were discussed in a number of lectures by scientists from Poland and Germany: the quality of hempseed oil depending on the sowing density and the harvest time of hemp inflorescence, a new biostimulator to increase crop resistance to draught, a pilot plant for the bioconversion of recyclable resources used in industry, and the use of enzyme-modified crops for creating composite materials based on polypropylene.

Scientists from Slovakia spoke about the recent achievements in flax production biotechnology. Useful information was presented at the conference on the problems of the extraction, processing, and application of rapeseed proteins; the application of a fluidized bed technology for sparing processing of rapeseed flour; biofuel and green chemicals production; the production of hydrogen from glycerol and cellulose; and the resistance of yellow natural pigments to UV radiation.

The participants of the conference discussed the following topics: the selective coating of plants in a fluidized bed, the influence of deoxygenation on the quality of flaxseed oil, modern improved technologies of the utilization of green waste, the fermentative transesterification of rapeseed oil using methyl acetate, and the influence of the sowing density on the profitability of hemp biomass production.

The two concluding lectures were devoted to biodiesel fuel. The German scientists who delivered the lectures discussed the prospects for the behavior of biodiesel fuel from the viewpoint of its fluidity in a cooled state depending on the raw materials used in its production. They also spoke about the possibility of improving the properties of biodiesel fuel using epoxidized fatty ethers.

The problems discussed at the conference are of great importance for both pure and applied science. The close interrelation between chemistry, biochemistry, biology, agriculture, and the chemical industry can be traced in the presented lectures and reports.

The next conference will be held in June 2010 in Magdeburg (Germany).

The conference materials will be published by "Nova Science Publishers" (New York, United States). One copy will be given in 2010 to the library of the Institute of Chemical Physics, Russian Academy of Sciences.

G. E. Zaikov

L. L. Madyuskina 